\title{
NAT2 GENE POLYMORPHISM IN BLADDER CANCER: A STUDY FROM NORTH INDIA
}

\author{
RAMA D. MITTAL, DAYA S.L. SRIVASTAVA, ANIL MANDHANI \\ Department of Urology, Sanjay Gandhi Post Graduate Institute of Medical Sciences, Lucknow, India
}

\begin{abstract}
Purpose: This study was conducted to examine: 1) whether the NAT2 genotypes are risk factors for bladder cancer, 2) to study possible association of tobacco usage with NAT2 genotype of these patients.

Materials and Methods: This case control study was undertaken over a period of 19 months and included 101 bladder cancer patients and 110 controls. The NAT2 genotypes were identified by PCR-RFLP method in peripheral blood DNA samples. Genotypes frequencies and the association of the genotypes among patients and controls group were assessed by $\chi 2$ test and Fisher exact test.

Results: The NAT2 fast acetylator genotype frequency of slow or fast acetylator genotypes was not significant in bladder cancer patients alone $(\mathrm{OR}=1.18,95 \%$ CI: $0.69-2.03$, $\mathrm{p}$ value $=0.583)$ or combination with tobacco users $(\mathrm{OR}=0.84,95 \% \mathrm{CI}: 0.328-2.125, \mathrm{p}$ value $=0.813)$ when compared with controls.

Conclusion: These data demonstrate that the NAT2 fast or slow acetylators genotype did not associated with the risk of developing bladder cancer in North Indian population when compared with controls.
\end{abstract}

Key words: bladder neoplasms; risk; tobacco; arylamine N-Acetyltransferase; polymorphism genetics Int Braz J Urol. 2004; 30: 279-88

\section{INTRODUCTION}

$\mathrm{N}$-acetyltransferases 2 (NAT2) is one of the phases II enzyme that participate in the bioconversion of heterocyclic arylamines into electrophilic nitrenium ions, which are important ultimate carcinogens that are directly implicated in tumor initiation process $(1,2)$. It expresses at high level in liver, and encoded by a polymorphic gene presenting several nucleotide substitutions. Consequently the presence of the different alleles in each individual genome produces a broad range of metabolic phenotypes that vary from fully active rapid metabolizers to the less active alleles of slow metabolizers (3).

Enzymatic activation and detoxification of carcinogens is a major principle in chemical carcinogenesis $(4,5)$. Many chemical and dietary carcinogens, such as nitrosoamines and arylamines derived from dietary fat as well as tobacco users' product, acquire bioactivation and deactivation by NATs enzymes. N-acetyltransferase- 2 catalyze the activation and for deactivation of a wide variety of aromatic amines, heterocyclic amines, and hydrazine drugs. This suggests that polymorphism of genes encoding metabolic enzymes may represent potential risk factors (6-8).

Recent molecular epidemiological studies have analyzed the relationship between various metabolic enzymes, such as $\mathrm{N}$-acetyltransferases (NATs), cytochrome P450 (CYP) and glutathione S- 
transferases (GSTs) in bladder and prostate cancer to determine as biomarkers $(9,10)$. In humans, hereditary differences in $\mathrm{N}$-acetylation activity have lead to phenotypic classification of individual as rapid or slow acetylators.

It has been reported that genetically variable NATs, CYP P450 and GSTs are involved in the metabolism of drugs, carcinogens and natural products; and therefore act as candidate genes for cancer susceptibility $(8,11)$. It is known that human express two forms of $\mathrm{N}$-acetyltransferases: NAT1 and NAT2; both genes are polymorphic. Thus for 24 NAT1 and 26 NAT2 alleles have been identified in humans. A recent review describes the nucleotide and aminoacid changes associated with various alleles and deduced phenotype from genotype. It also summarized results of molecular epidemiologic studies assessing the association of NAT1 and NAT2 genotypes with cancer risk of bladder, colon, breast, lung, head and neck and prostate $(12,13)$.

Although, some of these studies suggest that NAT1 and NAT2 polymorphisms may or may not be influence the susceptibility with these cancers. Recent studies have not supported a relationship between NAT1 genotypes and N-acetylation activity $(14,15)$. Furthermore, NAT2 has been reported to exhibit a polymorphism $(16,17)$, resulting in the potential expression of four mutant alleles (M1, M2, M3, M4), which can be identified by RFLP analysis following NAT2 PCR. NAT2 activity is predicted from the detected combination of these NAT2 alleles. Presence of at least one wild type alleles results in rapid acetylators where as the carriage of 2 mutant alleles results as a slow acetylator (16). The slow allele is present in up to $90 \%$ in some Arab population, 40$60 \%$ of Caucasians including Indians, 5-25\% East Asian (18-20) and 74\% in South Indians (21). It has been reported that slow acetylators may be at increased risk of bladder and prostate cancer when exposed to environmental arylamines carcinogens, due to their slower inactivation.

The present study was undertaken to examine NAT2 polymorphism and to evaluate whether, fast or slow acetylator phenotype is associated with increased risk of bladder cancer when compared with the controls. We also try to examine the association between NAT2 polymorphism with clinical stage and pathological grade of bladder cancer.

\section{MATERIALS AND METHODS}

Subjects: The study group consisted of 101 bladder cancer patients (all were transitional cell carcinoma, out of them $32 \%$ were grade 1 tumor, $20 \%$ were grade 2 and $48 \%$ were grade 3 tumor) with mean age $\pm \operatorname{SD}(57.29 \pm 13.40)$ and 110 controls with mean age $\pm \operatorname{SD}(56.71 \pm 13.95)$. Ethnic origin of cases and controls were rural area (not industrial area). There were no statistical differences in age of patient and control group.

Blood samples were obtained between December 2001 and December 2003 from patient group and control group, and patient data were obtained from medical records of patients. This study was approved by ethical committee of health care and research, of SGPGI under the guidelines of ministry of education, culture and science and technology.

The diagnosis of prostate cancer and bladder cancer patients was confirmed histopathologically in the study group. The control group consisted of age matched 110 normal healthy individuals. Serological (prostate serum antigen), physical (digital rectal examination) and radiological examination were performed in all controls individuals in order to exclude the possibility of malignancy. The inclusion criteria for the controls were absence of prior history of cancer or pre-cancerous lesions.

The consumption of tobacco in any form (cigarette bidi - a kind of cigarette used in rural area by the villagers) smoking, chewing tobacco in beetle leaf or gutka etc.) in both groups (cases and controls) was noted through a detailed questionnaire.

\section{PCR-RFLP and Alleles Genotyping}

Genomic DNA was isolated from peripheral leucocytes by Proteinase -K digestion and phenol/ chloroform method (22). The NAT genotypes were determined using the PCR-RFLP as described previously by Vatsis et al. 1995 (3). 1093 bp PCR product was generated by polymerase chain reaction (Figure-1) using the following primer: 
Forward 5'-TCTAGCATGAATCACTCTGC-3' Reverse 5' - GGAACA AATTGG AC TTGG -3'

Genomic DNA $200 \mathrm{ng}$ to $500 \mathrm{ng}$ was added to a PCR mixture, composed of 18.5 pmol of each primer, 200 micromol dNTP (Banglore Gennai, India), 1.5 unit of Taq polymerase (Banglore Gennai, India), and PCR buffer (Banglore Gennai, India) composed of $10 \mathrm{mmol} / \mathrm{mL}$ Tris $\mathrm{HCl} \mathrm{pH}=8.4,50$ $\mathrm{mmol} / \mathrm{mL} \mathrm{KCl}$ and $2.5 \mathrm{~mol} / \mathrm{mL} \mathrm{MgCL} 2$ ) in a total volume of $50 \mu \mathrm{L}$. We used PTC-100 (Programmable Temperature Control System) for polymerase chain reaction. The reaction mixture was subjected to initial denaturation at $94^{\circ} \mathrm{C}$ for $5 \mathrm{~min}$, followed by 35 cycles performed at denaturation $\left(94^{\circ} \mathrm{C}, 1 \mathrm{~min}\right)$, annealing $\left(58.5^{\circ} \mathrm{C}, 1 \mathrm{~min}\right)$ and extension $\left(72^{\circ} \mathrm{C}, 1 \mathrm{~min}\right)$. The final extension was done at $72^{\circ} \mathrm{C}$ for $10 \mathrm{~min}$. Following PCR, $7 \mu \mathrm{L}$ of PCR products were taken in 4 different tubes and digested with 4 separate enzymes including $\mathrm{Kpn} 1$ for NAT2*5 (M1) allele, at $37^{\circ} \mathrm{C}$ for $2 \mathrm{~h}$; Taq1 for NAT2*6 (M2) allele, at $56^{\circ} \mathrm{C}$ for $4 \mathrm{~h}$; BamH1 for NAT2*7 (M3) allele at $37^{\circ} \mathrm{C}$ for $2 \mathrm{~h}$; and Msp1/Alu1 for NAT2*14 (M4) allele at $37^{\circ} \mathrm{C}$ for $2 \mathrm{~h}$. Digested product runs on $2 \%$ agarose gels for M1, M3, M4 alleles and 3\% agarose gels for M2 allele (3). If the allele could not be identified as M1, M2, M3 or M4 after digestion, then the remaining allele were identified as a NAT2 $* 4$ (wild type) allele; since the wild type allele possess the entire restriction site. The NAT rapid acetylator genotypes are wild type (WT) allele, homo or heterozygotes (WT/WT, WT/M1, WT/ M2, WT/M3 or WT/M4), whereas the slow acetylator genotypes are those with 2 mutant alleles (M1/M1, M1/M2, M1/M3, M1/M4, M2/M2, M2/M3, M2/M4, M3/M3, M3/M4 and M4/M4).

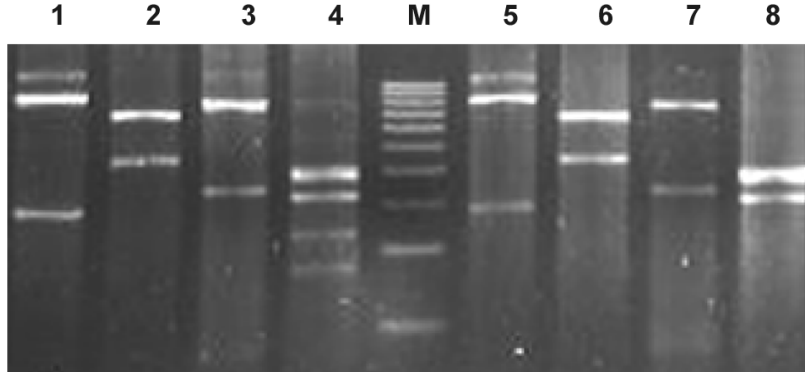

Figure 1 - PCR product from amplification of NAT2 analyzed on 2\% agarose. Lane $M-100$ bp ladder, lane 1, 2, 3, and 4 are in control samples and lane 5, 6, 7 and 8 are in bladder cancer patients. Lane 1 and 5 indicate BamH1 digestion (NAT2*7), lane 2 and $6 \mathrm{Kpn} 1$ digestion $(N A T 2 * 5)$, lane 3 and 7 Alu1 digestion $(N A T 2 * 14)$, lane 4 and 8 Taq1 digestion $(N A T 2 * 6)$.

\section{Statistical Analysis}

Statistical analysis was done with SPSS software. Difference in genotype prevalence and association between case and control group were assessed by the Chi square and Fisher exact tests. Odds ratios (OR) and its 95\% confidence interval (CI) were obtained by summarizing data over 2 habit strata (tobacco users / non-users). Multivariate analysis, correlation coefficient, odds ratios, $\mathrm{p}$ value (two-sided tests) and 95\% CI were used to describe the strength of association.

\section{RESULTS}

The frequency of NAT2 slow or fast acetylator genotypes was not significant in bladder cancer patients $(\mathrm{OR}=1.18,95 \%$ CI: $0.69-2.03$, p value $=0.583)$ in comparison to controls (Table-1).

Table 1 - Frequency of NAT2 phenotypes in bladder cancer patients in comparison to controls.

\begin{tabular}{lccccc}
\hline Patients & \multicolumn{2}{c}{ NAT2 phenotype } & Chi-square & p Value & OR (95\% CI) \\
& Slow-acetylators & Fast-acetylators & & & 1.0 (Ref.) \\
Controls $(\mathrm{n}=110)$ & $59(53.64 \%)$ & $51(45.36 \%)$ & & & \\
$\begin{array}{l}\text { Bladder } \\
\text { cancer }(\mathrm{n}=101)\end{array}$ & $51(50.5 \%)$ & $50(49.50 \%)$ & 0.36 & 0.583 & $1.18(0.69-2.03)$ \\
\hline
\end{tabular}


Table 2 - Risk of bladder cancer according to combination of NAT2 genotypes with tobacco users.

\begin{tabular}{lcc}
\hline Tobacco users & Controls $(\mathbf{n}=\mathbf{1 1 0})$ & Ca Bladder $(\mathbf{n}=\mathbf{1 0 1})$ \\
\hline Non-users & & \\
Slow-phenotype & $45(56.3 \%)$ & $28(48.3 \%)$ \\
Fast-phenotype & $35(43.7 \%)$ & $30(51.7 \%)$ \\
P value & & 0.391 \\
OR $(95 \%$ CI) & 1.0 (Ref.) & $1.378(0.669-2.715)$ \\
Tobacco-users & & \\
Slow-phenotype & $14(46.6 \%)$ & $22(51.2 \%)$ \\
Fast-phenotype & $16(54.4 \%)$ & $21(48.8 \%)$ \\
p value & & 0.813 \\
OR $(95 \%$ CI) & $1.0($ Ref.) & $0.835(0.328-2.125)$ \\
\hline
\end{tabular}

We analyzed the effect of NAT2 genotypes and tobacco users on the risk of bladder cancer in comparison to controls. We did not observe association between slow phenotypes and tobacco users with bladder cancer in our population (Table-2).

We divided clinical stage of tumor into 2 groups: $\mathrm{T} 1$ group (Ta-b and $\mathrm{Ti})$ and $\mathrm{T} 2$ in another group $(\mathrm{T} 2 \mathrm{a}-\mathrm{b}+\mathrm{T} 3+\mathrm{T} 4)$; and we found that NAT2 slow acetylator genotype was not significant in these groups when compared to controls (Table-3).

We also divided pathological findings into 3 groups: well differentiated (Grade-1), moderately differentiated (Grade-2) and poorly differentiated (Grade-3). We observed that NAT2 slow acetylator genotype were insignificant with any grade when compared with controls (Table-4).

\section{COMMENTS}

The results presented demonstrated that NAT2 genotype show no relationship to bladder cancer risk when considered alone $(\mathrm{OR}=1.18,95 \%$ CI: $0.69-2.03$, $p$ value $=0.583$ ) or in combination with tobacco users $(\mathrm{OR}=0.84,95 \% \mathrm{CI}: 0.328-2.125, \mathrm{p}$ value $=0.813)$ in comparison to controls. We also tried to correlate clinical stage and pathological grade with NAT2 genotype in bladder cancer, but no association was found.

Our findings agree with previous studies (23) that showed no relationship of NAT2 genotype to bladder cancer risk when considered alone or in combination with smoking. But several studies have demonstrated that low activity is doubtless a risk

Table 3 - Frequency of $N$-acetyltransferase-2 genotypes of bladder cancer patients categorized by stage of the disease.

\begin{tabular}{lcccc}
\hline & \multicolumn{2}{c}{ NAT2 phenotype } & p Value & OR (95\% CI) \\
& Slow-acetylators & Fast-acetylators & & \\
\hline Controls $(\mathrm{n}=110)$ & $59(53.64 \%)$ & $51(45.36 \%)$ & & 1.0 (Ref.) \\
Bladder & & & & \\
cancer $(\mathrm{n}=101)$ & & & & \\
T1 stage $(\mathrm{n}=61)$ & $29(47.55 \%)$ & $32(52.45 \%)$ & 0.523 & $0.78(0.42-1.46)$ \\
T2 + T3 + T4 stage $(\mathrm{n}=40)$ & $21(52.50 \%)$ & $19(47.50 \%)$ & 1 & $0.96(0.46-1.97)$ \\
\hline
\end{tabular}


Table 4 - Frequency of N-acetyltransferase-2 genotypes of bladder cancer patients categorized by pathologic grade of differentiation.

\begin{tabular}{lcccc}
\hline & \multicolumn{2}{c}{ NAT2 phenotype } & p Value & OR (95\% CI) \\
& Slow-acetylators & Fast-acetylators & & \\
\hline Controls $(\mathrm{n}=110)$ & $59(53.64 \%)$ & $51(45.36 \%)$ & & 1.0 (Ref.) \\
Bladder & & & & \\
cancer $(\mathrm{n}=101)$ & & & & \\
Grade-1 $(\mathrm{n}=40)$ & $18(45 \%)$ & $22(55 \%)$ & 0.363 & $0.71(0.34-1.46)$ \\
Grade-2 $(\mathrm{n}=26)$ & $14(53.85 \%)$ & $12(46.15 \%)$ & 1 & $1.01(0.43-2.38)$ \\
Grade-3 $(\mathrm{n}=35)$ & $18(51.43 \%)$ & $17(48.57 \%)$ & 0.848 & $0.91(0.43-1.96)$ \\
\hline
\end{tabular}

factor for bladder cancer, particularly for those individuals who smoke or who are exposed to specific occupational hazards $(24,25)$. According to the current theory of the role of $\mathrm{N}$-acetyltransferases (NAT1 and NAT2) in bladder cancer etiology, a decrease of arylamine $\mathrm{N}$-acetylation rates in the liver enforces N-hydroxylation mediated by CYP4501A2, which in turn leads to increased concentrations of hydroxylamines in the urinary bladder (26).

Polymorphisms of NAT and CYP enzymes that activate or detoxifying carcinogens and mutagens were believed to play crucial role in carcinogenesis. NAT2 enzyme has been shown to activate carcinogenic aromatic amines, which can arise from tobacco products or dietary intakes or environmental exposures $(8,10)$. Human acetylation polymorphism influences both the metabolic activation (Oacetylation) and deactivation ( $\mathrm{N}$-acetylation) of aromatic amines via the polymorphic expression of NAT2. It has been hypothesized that the increased susceptibility to urinary bladder cancer for slow acetylators is associated with the decreased deactivation of aromatic amines in the liver, so that excess hydroxylated aromatic amines reach the bladder epithelium where they can induce further activation step (27). The deactivation pathway can compete with activation pathway (N-hydroxylation and O-acetylation) (6). Whether NAT serves as an activating or deactivating enzyme depends on the final consequence of the competition of all these pathways, which is related to the polymorphism of CYP enzymes. Therefore, without studies on pharmacogenetics and cancer epidemiology, predicting any association of acetylator status with certain cancer is difficult.

This suggests that the association of metabolic enzyme gene polymorphisms with bladder cancer may differ according to the metabolic enzymes (NAT, CYP or GST) and ethnic population under study. Perhaps different environmental carcinogens in different countries determine whether $\mathrm{O}$-acetylation or $\mathrm{N}$-acetylation is the major pathway of that type of disease. However, because of limited data on metabolic pathway of various aromatic amines, further studies are mandatory to address this discrepancy.

In conclusion, this study indicates that NAT2 genotype exhibits non-significant association with the risk of developing bladder cancer, either alone or with tobacco users, or pathological grade, or clinical stage of disease.

\footnotetext{
The Director of Sanjay Gandhi Post Graduate Institute of Medical Science provided the necessary facilities. Daya Shankar Lal Srivastava is research fellow supported by the Council of Scientific and Industrial Research, New Delhi, India.
} 


\section{REFERENCES}

1. Hein DW: Acetylator genotype and arylamine induced carcinogenesis. Biochem Biophys Acta. 1988; 948: 3766.

2. Hein DW, Doll MA, Gray K, Rustan TD, Ferguson RJ: Metabolic activation of N-hydroxy-2acetylaminofluorene by NAT1 and NAT2 in colon cytosols of Syrian hamster congenic at the NAT2 locus. Cancer Res. 1993; 53: 509-14.

3. Vatsis KP, Weber WW, Bell DA, Dupret JM, Evans DA, Grant DM, et al.: Nomenclature for Nacetyltransferase. Pharmacogenetics. 1995; 5: 1-17.

4. Ames BN, Durston WE, Yamasaki E, Lee FD: Carcinogens are mutagens: a simple test system combining liver homogenates for activation and bacteria for detection. Proc Natl Acad Sci. 1973; 70: 2281-5.

5. Miller EC: Some current perspectives on chemical carcinogenesis in humans and experimental animals. Cancer Res. 1978; 38: 1479-96.

6. Hein DW, Doll MA, Rustan TD, Gray K, Feng Y, Fergusan R, et al.: Metabolic activation and deactivation of arylamine carcinogens by recombinant human NAT1 and polymorphic NAT2 acetyltransferases. Carcinogenesis. 1993; 14: 1633-8.

7. Cascorbi I, Brockmoller J, Mrozikiewicz PM, Muller A, Roots I: Arylamines N-acetyltransferase activity in man. Drug Metab Rev. 1999; 31: 489-502.

8. Caporaso N, Goldstein A: Cancer genes: single and susceptibility: exposing the difference. Pharmacogenetics. 1995; 5: 59-63.

9. Silverman DT, Rothman N, Devesa SS: Epidemiology of Bladder Cancer In: KN Syrigos, DG Skinner (eds.), Bladder Cancer. Biology, Diagnosis, Management. Oxford University Press Inc., New York; pp. 11-55.

10. Wadelius JE, Autrup JL, Stubbins MJ, Andersson SO, Johanason JE, Wadelius C, et al.: Polymorphism in NAT2, CYP2D6, CYP2C19 and GSTP1 and their association in prostate cancer. Pharmacogenetics. 1999; 9: 333-40.

11. Guengerich FP: Influence of nutrients and dietary materials on Cytochrome P-450 enzymes. Am J Clin Nutr. 1995; 61: 651-58.

12. Hein DW, Doll MA, Fretland AJ, Leff MA, Webb SJ, Xiao GH, et al.: Molecular genetics and epidemiology of the NAT1 and NAT2 acetylation polymorphisms. Cancer Epidemiol Biomarkers Prev. 2000; 9: 29-42.

13. Turesky RJ, Lang NP, Butler MA,Teitel CH, Kadlubar FF. Metabolic activation of carcinogenic heterocyclic amines by human liver and colon. Carcinogenesis. 1991; 12: 1839-45.

14. Grant DM, Hughes NC, Janezic SA, Goodfellow GH, Chen HJ, Gaedigk A, et al.: Human acetyltransferase polymorphisms. Mutat Res. 1997; 376: 61-70.

15. Stern MC, Johnson LR, Bell DA, Taylor JA: XPD codon 751 polymorphism, metabolism genes, smoking, and bladder cancer risk. Cancer Epidemiol Biomarkers Prev. 2002; 11:1004-11.

16. Inatomi $\mathrm{H}$, Katoh $\mathrm{K}$, Kawamoto $\mathrm{T}$, Matsumoto $\mathrm{T}$ : NAT2 gene polymorphism as a possible biomarker for susceptibility to bladder cancer in Japanese. Int $\mathbf{J}$ Urol.1999; 6: 446-54.

17. Hamasaki $\mathrm{T}$, Inatomi $\mathrm{H}$, Katoh $\mathrm{K}$, Aono $\mathrm{M}$, Ikuyama T,Muratani T, et al.: NAT2 gene polymorphism as a possible biomarker for susceptibility to prostate cancer in Japanese. Int J Urol. 1999; 6: 446-54. (Erratum in: Int J Urol 1999; 6: 592).

18. Lin HJ, Han C-Y, Lin BK, Hardy S: Ethnic distribution of slow acetylator mutation in the polymorphic Nacetyltransferase (NAT2) gene. Pharmacogenetics. 1994; 4: 125-34.

19. Xie HG, Xu ZH, Ou-Yang DS, Shu Y, Yang DL, Wang JS, et al.: Meta-analysis of phenotype and genotype of NAT2 deficiency in Chinese population. Pharmacogenetics. 1997; 7: 503-14.

20. Woolhouse NM, Qureshi MM, Bastaki SM, Patel M, Abdulrazzaq Y, Bayoumi RA: Polymorphic Nacetyltransferase (NAT2) genotyping of Emiratis. Pharmacogenetics.1997; 7: 73-82.

21. Anitha A, Banerjee M: Arylamine $\mathrm{N}$-acetyltransferase 2 polymorphism in the ethnic population of South Indians. Int J Mol Med. 2003; 11: 125-31.

22. Sambrook J, Fritsch E, Maniatis T: Molecular Cloning - A Laboratory Manual, 2nd ed. New York, Cold Spring Harbor Laboratory Press. 1989.

23. Taylor JA, Umbach DM, Stephens E, Castranio T, Paulson D, Robertson C, et al.: The role of $\mathrm{N}$ acetylation polymorphism in smoking-associated bladder cancer: evidence of a gene-gene-exposure three-way interaction. Cancer Res. 1998; 58: 360310.

24. Marcus PM, Hayes RB, Vineis P, Garcia-Closas M, Caporaso NE, Autrup H, et al.: Cigarettes smoking, $\mathrm{N}$-acetyltransferase 2 acetylation status, and bladder cancer risk: a case series meta-analysis of geneenvironmental interaction. Cancer Epidemiol Biomarkers Prev. 2000; 9: 461-7.

25. Marcus PM, Vineis P, Rothman N: NAT2 slow acetylation and bladder cancer risk: a meta-analysis 
of 22 case control studies conducted in general population. Pharmacogenetics. 2000; 10: 115-22.

26. Lang NP, Kadlubar FF: Aromatic and heterocyclic amine metabolism and phenotyping in humans. Prog Clin Biol Res. 1991; 372: 33-47.
27. Brockmoller J, Cascorbi I, Kerb R, Roots I: Combined analysis of inherited polymorphism in arylamine $\mathrm{N}$ acetyltransferases M1 and T1, microsomal epoxide hydrolase, and CYP 450 enzyme as modulator of bladder cancer risk. Cancer Res. 1996; 56: 3915-25.

Received: March 9, 2004 Accepted: May 5, 2004

\author{
$\overline{\text { Correspondence address: }}$ \\ Dr. Rama Devi Mittal \\ Department of Urology \\ SGPGIMS, Raibarelly Road, \\ Lucknow-226014, India \\ Fax: + 91522668017 \\ E-mail: rmittal@ sgpgi.ac.in
}

\section{EDITORIAL COMMENT}

There is a long-lasting discussion, whether foreign-compound-metabolizing enzymes may modify the risk of chemically induced cancer. Phenotyping studies in the late sixties provided evidence that slow acetylators are at increased risk for bladder cancer (1-3). It was hypothesized that in rapid acetylators arylamines, as contained in aniline dyes or cigarette smoke (e.g. 4-aminobiphenyl), are detoxified by $\mathrm{N}$-acetylation in the liver and excreted in the urine. In contrast, low $\mathrm{N}$-acetylation activity leads to increased formation of $\mathrm{N}$-hydroxylated products. These hydroxylamines may undergo further O-acetylation in the urinary bladder preferentially by arylamine $\mathrm{N}$-acetyltransferase 1 (NAT1), which was found to be expressed in the urinary epithelium (4). The product, arylamine acetoxyesters are unstable in the acid environment and disintegrate spontaneously to arynitrenium ions. These highly reactive radicals may well interact with proteins and DNA of bladder epithelial cells forming adducts (5). A number of in vitro studies gave evidence for this theory. However to date, occupational exposure is fortunately decreasing.
The current carefully performed study of Mittal et al. (6) published in this issue, showed in a sample of 101 North-Indian bladder cancer patients and 110 controls that the NAT2 polymorphism did not play a role as susceptibility factor. Also after stratification to smoking habits, differences did not reach statistical significance.

A meta-analysis of 22 published case-control phenotyping and genotyping studies conducted in a total of 2496 cases and 3340 controls in different populations, however, revealed that slow acetylators had a $40 \%$ increased risk compared to rapid acetylators (odds ratio 1.4, 95\% confidence interval 1.2-1.6) (7). In particular, the largest genotyping studies showed gene-environment interactions. Slow acetylators with a smoking history of more than 50 pack years had a 2-fold higher risk of bladder cancer, as did subjects with typical risk occupations. Subjects meeting both criteria showed the highest risk (8). Differences observed between different ethnicities and locations were thought to be due to distinct tobacco blends preferred by the consumers. 
In the new study of Mittal et al. in Northern India, only 43 out of 101 bladder cancer patients and 30 out of 110 controls were classified as tobacco-users (6). In contrast, in the large European study showing NAT2 gene-environment interactions, $70 \%$ of all patients were smokers (7). However, in this study also no significant association of NAT2 to bladder cancer risk was observed without consideration of smoking or occupational exposure.

Therefore, as correctly stated by Mittal et al. (6), NAT2 may not be considered as a single individual risk factor for urinary cancer. There is strong evidence that the environmental influence is of essential impact and possibly the interaction with other genes e.g. NAT1 should be investigated to estimate the overall risk of a large sample. Indeed, Bell et al. (9) reported two important facts: NAT1*10 was found to provide enhanced activity in bladder tissue compared to NAT $1 * 4$ and moreover, the frequency of NAT1*10 was increased among bladder cancer patients. However, these results are conflicting (10) and recently we were able to show that NAT $1 * 10$ does not alter enzyme activity towards ex-vivo formation of $\mathrm{N}$-acetyl p-amino benzoic acid (11). We observed a significant decrement of NAT $1 * 10$ genotypes among 425 bladder cancer patients; the odds ratio, adjusted for age, gender, and smoking was 0.65 (95\%-C.I. 0.46$0.91 ; \mathrm{p}=0.013)(12)$. Considering the NAT2 genotype, a clear under-representation of NAT $1 * 10$ genotypes among rapid NAT2 genotypes in the cases studied (odds ratio 0.39; 95\%-C.I. 0.22-0.68; $\mathrm{p}=0.001$ ), and a gene-gene-environment interaction was observed. NAT $2 *$ slow/NAT $1 * 4$ genotype combinations with a history of occupational exposure were 5.96 (2.96-12.0)-times more frequent in cancer cases than in controls without risk occupation $(\mathrm{p}<0.0001)$, suggesting that individuals with NAT $2 * 4$ and NAT $1 * 10$ alleles are at a significantly lower risk for bladder cancer, particularly when exposed to environmental risk factors.

Due to inter-ethnical differences of polymorphic traits, smoking and dietary habits, investigations on the role of polymorphic genes as susceptibility factor for complex diseases like cancer may lead to different results in different populations. There is also some evidence for the predominance of rapid acetylators among colon cancer patients. The role of NAT1 however, is still the subject of considerable investigation. The functional significance of the diverse point mutations in NAT1 is not yet fully understood and there are a growing number of distinct haplotypes being identified. Therefore, studies of NAT1 and NAT2 are sometimes difficult to compare, since different methodologies and numbers of alleles were investigated. However, consideration of genegene-environment interactions and the possibility of identifying in parallel a number of SNPs, using modern genotyping techniques, will help to elucidate the impact of these interesting genes particularly in the etiology of cancer.

\section{REFERENCES}

1. Cartwright R A, Glashan RW, Rogers HJ, Ahmad RA, Barham Hall D, Higgins E, et al.: Role of Nacetyltransferase phenotypes in bladder carcinogenesis: a pharmacogenetic epidemiological approach to bladder cancer. Lancet. 1982; 2: 842-5.

2. Lower G M Jr, Nilsson T, Nelson CE, Wolf H, Gamsky TE, Bryan GT: N-acetyltransferase phenotype and risk in urinary bladder cancer: approaches in molecular epidemiology. Preliminary results in Sweden and Denmark. Environ Health Perspect. 1979; 29: 71-9.

3. Vineis P, Ronco G: Interindividual variation in carcinogen metabolism and bladder cancer risk. Environ Health Perspect. 1992; 98: 95-9.

4. Kloth MT, Gee RL, Messing EM, Swaminathan S: Expression of N-acetyltransferase (NAT) in cultured human uroepithelial cells. Carcinogenesis. 1994; 15: 2781-7.

5. Hein DW, Doll MA, Rustan T D, Gray K, Feng Y, Grant DM: Metabolic activation and deactivation of arylamine carcinogens by recombinant human NAT1 and polymorphic NAT2 acetyltransferases. Carcinogenesis. 1993; 14: 1633-8.

6. Mitta RA, Srivastava DSL, Mandhani A: NAT2 gene polymorphism in bladder cancer: a study from North India. Int. Braz J Urol. 2004, 30: 279-88.

7. Marcus PM, Vineis P, Rothman N: NAT2 slow acetylation and bladder cancer risk: a meta-analysis of 22 case-control studies conducted in the general population. Pharmacogenetics. 2000; 10: 115-2.

8. Brockmöller J, Cascorbi I, Kerb R, Roots I: Combined analysis of inherited polymorphisms in arylamine $\mathrm{N}$ acetyltransferase 2, glutathione S-transferase M1 and 
T1, microsomal epoxide hydrolase, and cytochrome P450 enzymes as modulators of bladder cancer risk. Cancer Res. 1996; 56: 3915-25.

9. Bell DA, Badawi AF, Lang NP, Ilett KF, Kadlubar FF, Hirvonen A: Polymorphism in the $\mathrm{N}$-acetyltransferase 1 (NAT1) polyadenylation signal association of NAT $1 * 10$ allele with higher $\mathrm{N}$-acetylation activity in bladder and colon tissue. Cancer Res. 1995; 55: 52269.

10. Okkels H, Sigsgaard T, Wolf H, Autrup H: Arylamine $\mathrm{N}$-acetyltransferase 1 (NAT1) and 2 (NAT2) polymor- phisms in susceptibility to bladder cancer: the influence of smoking. Cancer Epidemiol Biomarkers Prev. 1997; 6: 225-31.

11. Bruhn C, Brockmöller J, Cascorbi I, Roots I, Borchert $\mathrm{H}$ : Correlation between genotype and phenotype of the human arylamine $\mathrm{N}$-acetyltransferase type 1 (NAT1). Biochem. Pharmacol. 1999; 58: 1759-64.

12. Cascorbi I, Roots I, Brockmöller J: Association of NAT1 and NAT2 polymorphisms to urinary bladder cancer: significantly reduced risk in subjects with NAT1*10. Cancer Res. 2001, 61: 5051-6.

\section{Dr. Ingolf Cascorbi \\ Professor and Head, Institute of Pharmacology University Hospital Schleswig-Holstein Kiel, Germany}

study to appear shortly (2) provides more details on the effects of NAT2 genotype misclassification on sample sizes required to detect the association with bladder cancer in smokers. The authors are encouraged to continue these interesting studies with larger sample sizes and more comprehensive NAT2 genotype procedures.

\section{REFERENCES}

1. Hein DW, Doll MA, Fretland AJ, Leff MA, Webb SJ, Xiao GH et al.: Molecular genetics and epidemiology of the NAT1 and NAT2 acetylation polymorphisms. Cancer Epidemiol Biomarkers Prev. 2000; 9: 29-42.

2. Deitz AC, Rothman N, Rebbeck TR, Hayes RB, Cho $\mathrm{W}-\mathrm{H}$, Zheng W, et al.: Impact of misclassification in genotype-exposure interaction studies: Example of Nacetyltransferase 2 (NAT2), smoking, and bladder cancer. Cancer Epidemiol Biomarkers Prev. 2004; 13 (9): (In Press).

Dr. David W. Hein

Professor and Chairman, Department of Pharmacology \& Toxicology

Director, Cancer Prevention \& Control Program University of Louisville School of Medicine Louisville, Kentucky, USA 


\section{EDITORIAL COMMENT}

The issue about whether acetylation rates are important in bladder cancer has been discussed for a long time, and different reports have come out. There also is considerable literature about the effect of smoking on bladder cancer so to make the assumption that the two might be additive is very reasonable. This paper looks at 101 bladder cancer patients and 110 con- trols. The studies have been done very carefully, and they conclusively show that there is no link between fast and slow acetylators and the development of bladder cancer and that smoking does not tip the balance. It is hoped this will lay to rest these questions.

The authors are to be commended on their paper.

Dr. Ralph W. de Vere White

Director, University California Davis Cancer Center Professor and Chair, Department of Urology Davis, California, USA 